\title{
A Comparative Study on the Problems faced by Senior citizens living in Institutions and Non- institutions in Mangaluru Taluk
}

\author{
${\text { Laveena } \text { D'Mello }^{1} \text { \& Meena Monteiro }}^{2}$ \\ ${ }^{1}$ Assistant Professor, Social Work Department, Srinivas Institute of Management Studies, \\ Mangalore, Karnataka, India. \\ ${ }^{2}$ Associate Professor, MSW Department, School of Social Work, Roshni Nilaya, Mangalore, \\ Karnataka, India \\ E-mail: lavynoronha@gmail.com
}

Type of the Paper: Case Study.

Type of Review: Peer Reviewed.

Indexed In: OpenAIRE

DOI: http://dx.doi.org/10.5281/zenodo.1004678.

Google Scholar Citation: IJCSBE

\section{How to Cite this Paper:}

D’Mello, Laveena., \& Monteiro, Meena. (2017). A Comparative Study on the Problems faced by Senior citizens living in Institutions and Non-institutions in Mangaluru Taluk. International Journal of Case Studies in Business, IT and Education (IJCSBE), 1(2), 52-59. DOI: http://dx.doi.org/10.5281/zenodo.1004678.

International Journal of Case Studies in Business, IT and Education (IJCSBE) A Refereed International Journal of Srinivas University, India.

(C) With Authors.

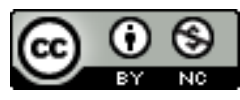

This work is licensed under a Creative Commons Attribution-Non Commercial 4.0 International License subject to proper citation to the publication source of the work.

Disclaimer: The scholarly papers as reviewed and published by the Srinivas Publications (S.P.), India are the views and opinions of their respective authors and are not the views or opinions of the S.P. The S.P. disclaims of any harm or loss caused due to the published content to any party. 


\title{
A Comparative Study on the Problems faced by Senior citizens living in Institutions and Non-institutions in Mangaluru Taluk
}

\author{
Laveena D’Mello ${ }^{1}$, Meena Monteiro ${ }^{2}$ \\ ${ }^{1}$ Assistant Professor, Social Work Department, Srinivas Institute of Management Studies, \\ Mangalore, Karnataka, India. \\ ${ }^{2}$ Associate Professor, MSW Department, School of Social Work, Roshni Nilaya, Mangalore, \\ Karnataka, India \\ E-mail: lavynoronha@gmail.com
}

\begin{abstract}
Ageing is a normal, common, universal and un-avoiding phenomenon. Ageing has three aspects biological, psychological and social. We are living in this busy world, it is the duty of each and every young ones to spend a little time for our elders, patient listening, loving talks and careful attention can relieve many of the psychological problems. It appears in India senior citizens have no right to live a life of dignity. Day by day they are getting shocks and traumas in one form or other, the past two decades the social scene, due to a number of factors, had undergone drastic changes with the joint family system breaking down. Today, nuclear families are the norm. In fact, for most people, growing old is time to be enjoyed. They mostly ignore the symptoms considering it as the signs of aging. Institutionalized elderly refers to the people above the age of sixty years who live in the institution and Non-institutional elderly means who stay in their own house alone, with their partner, children, and grandchildren together. The issues and problems are varied in any place be it in families or in the institution. It differs from person to person. The researchers came to know of various problems faced by them. Thus was interested to study the problems they face. The scope of the study is restricted to only 50 elderly in Mangalore city. 25 respondents are from institutions and 25 from those living in families. The aim is to draw a comparison between the problems faced by the elderly in each of these places. The objectives are to assess the problems faced by the elderly and to know their opinion on their stay. The respondents were selected adopting a simple random method of sampling.
\end{abstract}

Keywords: Senior citizen, Institutional, Non-institutional, old age, elderly population, family support.

\section{INTRODUCTION :}

Age sixty is usually considered the dividing line between middle and old age. However, it is recognized that chronological age is a poor criterion to use in making off the beginning of old age because there are such marked differences among individuals in the age at which aging actually begins. Because of better living conditions and better health care, most men and women today do not show the mental and physical signs of aging until the mid-sixties or even the early seventies. For that reason, there is a gradual trend toward using sixty-five, the age of retirement in many businesses, to mark the beginning of elderly. The elderly person represents a storehouse of knowledge and experience and reservoir of wisdom but is a highly vulnerable group in society. Their vulnerability increases with age. The vulnerability lies mainly in lack of employment, financial insecurity, ill health and neglect by society. Any system of social security of the elderly should address all these vulnerabilities. It has, therefore, to be a multidimensional program providing income security, health security, and emotional support while the family can provide the basic security. Two of the most difficult development's tasks of elder age relate to areas that are especially important for all adult - 
work and family life. Elderly people face adjustment problems in these areas that are similar in some respects to those they faced earlier but that are unique in many ways. In the family, elder men and women must adjust to depending on each other for companionship, to the lack of contact with, and influence over, their children and often to the loss of a spouse. Unmarried elderly people often face adjustment problems that are married or who have lost a spouse. The aging of the population along with changes in the family structure and shifts in intergenerational relations has brought into focus issues pertaining to the elderly in India. The growing visibility of old age homes in India points to the needs of elderly, which were not recognized earlier. The old age homes have sprung up to cater to the needs of the elderly from different socio-economic backgrounds. The interests of the elderly to spend their old age in sacred places, the migration of children in search of employment opportunities, their maladjustment in family and poverty of the elderly are the major reasons for the Indian elderly to shift to old age homes. But since the idea of living in old age homes is relatively new in India, the adjustment process of the old age home residents, their feelings of satisfaction and dissatisfaction and expectations from family members provide an interesting field of inquiry [1-2].

Today, the old age homes are indispensable as they are needed to take care of the lonely and forsaken elderly in the evening of their lives. Whenever the family does not provide full protection and security to the aged, the society has to share the burden of looking after them. Nowadays, old age homes are established to take care of the old. This idea of "institutionalization" of the aged has largely been borrowed from the western countries. In the context of the dynamic changes taking place in Indian society, the problem of the aged has assumed importance. There is a gap between the needs of old people and the availability of health and social service in these institutions. There is much research on the problem of the institutionalized old people abroad but in India, very little organized information is available about the problem of the aged living the families and in old age homes. However in recent times, as a result of the demographic transition, the rapid pace of industrialization and urbanization, the disintegration of joint family structures into nuclear ones, increasing participation of families in the non-agricultural labor force, the older people have become more vulnerable. The lack of familial support made elderly resort to old age homes run by private and or voluntary organizations for their care and support. Of the several consequences of such trends, one that causes serious concern is that of providing care to a large number of older persons to have a better quality of life. This has different dimensions and connotations. When it comes to older people, care which implies providing physical, social, economic and emotional implies instrumental support on a continuous and long-term basis. Health status is an important indicator of the Quality of Life of the elderly [3].

\section{STATISTICAL DATA OF ELDERLY PEOPLE IN INDIA :}

The elderly population (aged 60 years or above) account for $7.4 \%$ of total population in 2001. For males, it was marginally lower at $7.1 \%$, while for females it was $7.8 \%$. Among states, the proportion varies from around $4 \%$ in small states like Dadra \& Nagar Haveli, Nagaland Arunachal Pradesh, Meghalaya to more than $10.5 \%$ in Kerala. Both the shape and size of the elderly population is increasing over time. From $5.6 \%$ in 1961, it is projected to rise to $12.4 \%$ of the population by the year 2026. The sex ratio among elderly people was as high as 1028 in 1951 but subsequently dropped to about 938 in 1971 and finally reached 972 in 2001. The life expectancy at birth during 2002-06 was 64.2 for females as against 62.6 years for males. At age 60 average remaining length of life was found to be about 18 years (16.7 for males, 18.9 for females) and that at age 70 was less than 12 years (10.9 for males and 12.4 for females). There is a sharp rise in age-specific death rate with age from 20 (per thousand) for persons in the age group 60-64 years to 80 among those aged 75- 79 years and 200 for persons aged more than 85 years. The old-age dependency ratio climbed from $10.9 \%$ in 1961 to $13.1 \%$ in 2001 for India as a whole. For females and males, the value of the ratio was $13.8 \%$ and $12.5 \%$ in 2001 [4].

About 65 percent of the aged had to depend on others for their day-to-day maintenance. Less than $20 \%$ of elderly women but the majority of elderly men was economically independent. Among economically dependent elderly men $6-7 \%$ was financially supported by their spouses, almost $85 \%$ by their own children, $2 \%$ by grandchildren and $6 \%$ by others. Of elderly women, less than $20 \%$ depended on their spouses, more than $70 \%$ of their children, $3 \%$ on grandchildren and $6 \%$ or more on 
others including the non-relations. It Situation analysis of the elderly in India, 2011 of the economically independent men more than $90 \%$ as against $65 \%$ of women was reported to have one or more dependants. Among the rural elderly persons, almost $50 \%$ had a monthly per capita expenditure level between Rs. 420 to Rs. 775 and among the urban elderly persons; almost half of aged had monthly per capita expenditure of Rs. 665 and 1500 in 2002. Nearly 40\% of persons aged 60 years and above ( $60 \%$ of men and $19 \%$ of women) were working. In rural areas, $66 \%$ of elderly men and above $23 \%$ of aged women were still participating in the economic activity, while in urban areas only $39 \%$ of elderly men and about $7 \%$ of elderly women were economically active. Even in $2007-08$ only $50 \%$ men and $20 \%$ of women aged 60 years or more were literate through formal schooling. In rural areas, $55 \%$ of the aged with sickness and $77 \%$ of those without sickness felt that they were in a good or fair condition of health. In urban areas, the respective proportions were $63 \%$ and $78 \%[5]$.

The proportion of elderly men and women physically mobile decline from about $94 \%$ in the agegroup 60 - 64 years to about $72 \%$ for men and 63 to $65 \%$ for women of age 80 or more. Prevalence of heart diseases among the elderly population was much higher in urban areas than in rural parts. About 64 per thousand elderly persons in rural areas and 55 per thousand in urban areas suffer from one or more disabilities. Most common disability among the aged persons was a locomotors disability as $3 \%$ of them suffer from it. In age-groups beyond 60 years, the percentage of elderly women married was markedly lower than the percentage of men married. More than $75 \%$ of elderly males and less than $40 \%$ of elderly females live with their spouse. Less than $20 \%$ of aged men and about half of the women live with their children.

A review of the Indian government's Five Year Plans shows very limited and inconsistent concern for the elderly. The only welfare measure for the elderly considered by the government until the Seventh Five Year Plan was the running of old age homes. The Eighth and Ninth Plans, however, incorporated fairly more specific and comprehensive welfare measures for the elderly. Yet health care for the poor elders is not satisfactory. What the Indian government is doing for elders care can best be described as a situation of "vast undone and little done." Kerela has introduced some services for the elders such as the starting of day care centers for elderly. It is boon to the caretakers; therefore, starting off more number of daycare centers in the urban areas and mobile clinics in the rural areas is an urgent need. Senior-friendly public transport and toilets is another need. Sensitizing children regarding care of the elderly through schools is an urgent measure needed. Lack of hospitals for terminally ill and Alzheimer affected elders is another gap in India [6]. There is a huge gap in the supply and demand position of personnel for palliative care and home nursing and it needs immediate attention. Let the government acknowledge the fact the elders of today have contributed to the growth and culture of the country and let youngsters realize that their sacrifice and efforts have laid the foundation for their current position and hence it is the responsibility of the government and the family members to take care of the elder's needs instead of considering their prolonged life as a burden

\section{PROBLEMS OF ELDERS :}

Though aging is a natural stage of human life, it brings with the innumerable problems for the people who have grown old. Physical Problems: Old age is marked by digestive disorders such as difficulty in swallowing, inability to eat enough and to absorb nutrition, constipation, and bleeding. They have at least one chronic condition and many have multiple conditions. Sleeplessness is another problem of the elderly and lack of urine control are the common problems of the old age. Less saliva and less ability for oral hygiene in elder age increase the chance of tooth decay and infection. They face reducing eyesight makes it more difficult to read in low lighting and in smaller print. The speed with which individual reads and the ability to locate objects may also be impaired. Elder younger age spells risk for injury from falls that might not cause injury to a person. Hair usually becomes thinner and greyer. Hearing problems are common in elderly people. Heart functioning is less efficient in old age with a resulting loss of stamina. In addition, atherosclerosis can constrict blood flow. Bone and joint are thinning and shrinking as and when the age increases. This results in a loss of height (about two inches by age 80) and a bending towards the front and more diseases related to the bones and joints less efficient immune function is a mark of elder age. Lungs expand less well; thus, they 
provide less oxygen. Skin loses elasticity, becomes drier, and more lined and wrinkled. Mental Problems: Mental problems of elder age are depression. People with more negative age stereotypes will likely have higher rates of depression as they get older. Fear of crime in old age, especially among the frail, sometimes weighs more heavily than concerns about finances or health and restricts what they do. The fear persists in spite of the fact that elder people are victims of crime less often than younger people [7, 8 ]. Mental disorders afflict about $15 \%$ of people aged $60+$ according to estimates by the World Health Organization. Survey taken in 15 countries reported that mental disorders of adults interfered with their daily activities more than physical problems.

\section{CAUSES FOR PROBLEMS :}

Common conditions that contribute to a change of interest and recreational activities include physical, psychological and lifestyle changes in elderly and changes in interests. When they are in good physical condition, elderly people are often preoccupied with their health and with the bodily process. Frequently they tend to complain about their health and to exaggerate even the simplest ailment they have. The areas the elderly get affected with are, Health: Changes in health and energy are reflected in an increased interest in sedentary pursuits and a decreased interest in activities requiring strength and energy. As health gradually fails and as physical disabilities such as poor eyesight set in, the individual acquire an interest recreational activity that requires a minimum of strength, energy and can be enjoyed in the home. Economic status: Elder people who have inadequate money to meet their daily need often have to give up many of the interest that is important to them and concentrate on the ones they can afford, regardless of whether they are meaningful to them or meet their needs. Marital status: Just as unmarried men and women in early adulthood and middle age have more time and money to cultivate interest than do those who are married, so do the unmarried in elder age. Some of their interest may be new but most are carrying -over from younger years. Elderly people who have been accustomed to engaging in recreation with their spouses must make radical changes in their patterns after the loss of a spouse through divorce or death. Women accustomed to playing cards or going to community clubs with her husband may have to cultivate new recreational interests when she is left alone [9].

Living conditions: Elderly people lives have a marked influence on whether their earlier interests will persist or change. If they live in their own homes with family members, their interests are far more likely to remain static than if they go to live with married children or in a retirement home. Elderly persons who live in a home for the aged have recreation provided for them that are suited to their physical and mental abilities. Those who live in their own homes or with a married child have fewer opportunities for recreation, especially if their economic status is poor if failing health or transportation problems prevent them from participating in the community -sponsored recreational activities. Compulsory retirement: Because most industries, business, and governmental bureaus require workers to retire at certainly fixed ages, ranging from sixty to seventy years, they do not want to hire men or women who are approaching the mandatory retirement age because of the time, energy, and expense that would be involved in training them for the job. Hiring policies: When the personnel departments of business and industry are in the hands of younger people, the elder worker's difficulties in finding employment are greatly increased. Pension plans: There is a close correlation between the existence of a pension plan in business and industry and the failure to make use of workers over sixty-five years of age. Values: As values change, so do interest at every age. In elder age, value changes are common and usually toward conservatism. This affects the relative value they place on their interests. Elder people, for example, may come to value social contacts rather than hobbies as compensation for the loneliness caused by loss of a spouse. Social status: Elder people of the higher social groups usually have a wider range of interests than those of the lower groups. Many of these are carry over's of interest developed earlier in life [10].

\section{INSTITUTION :}

The population in India is increasing phenomenally with 70 million elder persons in 2000 projected to rise to 177 million by the year 2025 and 324 million by 2050. Further, a vast majority of the elder population in India live in rural area, 90 percent are from unorganized sector with no social security, 30 percent live below poverty line and another 33 percent just marginally over it. Voluntary 
Organization for Aged: There is numerous voluntary organization and India and Age - Care India, in particular, to know about the kind of activities are carrying on in the field of the care of the aged. Old Age Homes: The central or state governments, Municipal Bodies, philanthropic Societies, Voluntary Organization and Senior Citizens Welfare Association have set up homes for old or elderly citizens to provide them residential facilities and other allied needs, entertainment places to have physical and mental activities, creativity to combat loneliness and to have contacts and interaction with other people. At present, there are only some 300 homes in the country mostly in urban areas. The transition of Indian society from the traditional pre-industrial led to the emergence of nuclear families. These changes have seriously affected the social context the aged thereby exposing them to several serious problems. The demographic aging of the population may be attributed to various factors like the decrease in birth and death rates and increase in life expectancy at birth due to improvement in the general health and nutrition standards of the population. Insecurity, health, and financial problems are the major areas in which the elderly have needs and face problems and require help. Ageing is a phase of life and a biological process. Every organism that is boring must age with time and decay. The Right to Admission: No older person should be refused admission to a residential facility if they meet the basic admission requirements. If the manager of an old age home does refuse admission, he/she will have to provide reasons, in writing for the refuse. The Right to Refuse Admission: No older person can be placed in residential care without their consent unless their mental conditions render them incapable. In such cases, consent must be given by people authorized by the law to do so [11].

Institutionalization: In case of the aged need institutionalization it is the social worker who should help determine the suitability of the person for admission to the institution by conducting home visits and interviews with the aged and the family. Shifting an elderly to an institution means adjustments with the changed environment and that is not an easy process. The social workers need to prepare preferably beforehand so that their anxiety and apprehensions are minimized. It is necessary to understand and appreciate that after years of being an integral part of the family, the aged are faced with separation leading to a sense of vacuum and also the trauma of uncertainty regarding the kind of life may have to lead in an institution. The institution though may provide satisfactory physical comfort and friendly atmosphere, the loneliness, and the apathy reflect on the elderly, as they have to adjust to an environment of sickness and also death around them. Studies reveal that there is a tendency of the aged towards apathy, passive acceptance of life, negative feelings, self-criticism, depression, bitterness, and irritability. The social workers should be conscious of this and work with them in a manner that the elderly are able to adapt positively to newer situations. Pensions Portal: A Pension Portal has been set up by the Department of Pensions, Government of India, to enable senior citizens to get information regarding the status of their application, the amount of pension, documents required, if any, etc. The Portal also provides for lodging of grievances.

\section{FINDINGS :}

Majority of the respondents are belonging to the urban area and between the age group of 66 and 70 years. 60 percent of them are female and widows. Out of 50 respondents, $40 \%$ of them belong to the Christian religion and completed their SSLC education. Both institutional and non-institutional respondent's majority 74 percent of them are from nuclear family. 36 percent of respondents are living with children, 14 percent of respondents are living with spouses and 50 percent of respondents are living in an institution. 84 percent of them are not working and cannot do any work. 56 percent of the respondents they suffer poor eyesight problem, 72 percent of the respondents they face a herd of a hearing problem, 76 percent of the respondents they suffer from dementia, and 66 percent of them suffer from lack of appetite, and 76 percent of the respondents suffer from lack of sleep. If all these are physical aspects almost all will have one or the other diseases. 64 percent of the respondents they suffer hypertension, 86 percent of the respondents they suffer from joint pain, 36 percent of the respondents suffered from the cardiac problem, 68 percent of the respondents they suffer from blood sugar problem, 64 percent of the respondents they suffer cholesterol and gastric problems. 24 percent of respondent feel good about their health and 76 percent of respond feel poor about health. 68 percent of respondent they move around independently.24 percentage of respondent they not able to move around. 72 percent of respondents were suffering from loneliness. 32 percent of the 
respondents were feeling insecure and remaining 68 percent of respondents do not feel insecure. 84 percent of respondents feel that children/family members do not respect and remaining 16 percent of respondents do not have those feelings. 40 percentages of respondent's children will take care when they sick, and 50 percent respondent's institution will take care because they stay there and remaining 10 percent of respondents will suffer from nobody to take care of them. 76 percent of respondent feel that their family members have concern towards them and 24 percent think that they do not have concern towards them. 72 percent respondents have some or the other source of income may the interest from the bank for their deposit amount, government pension after retirement from a job, old age pension, rent from the houses or shops, etc but other 28 percent of the respondent does not have any source of income of their own. They are totally depending on their family members. 34 percent of the respondents were able to do manage their expenses on their own and 66 percent of respondents were not able to manage their expenses on own. 86 percent of the respondents they satisfied with present life. Majority of the respondents say that sometimes they have adjustment problems and they share an average relationship with their family members. Majority of them say that they always take active participation in the major activities of the family. In the case of disclosing their personal matter to others, the majority say that they then it only to some extent. Only occasionally they interact with their friends and neighbors according to the opinion of the majority. Majority of the respondents say that they share a good relationship with their spouse. Most of them are aware of the problems faced by the aged. Most of the elderly do not have an inferiority complex. Most of them are respected by their grandchildren at home as well as the society also. A good number of the respondents are economically secured and are also involved in social relationships by their children. Majority of them are worried about their health. Majority of the respondents feel happy living in an institution. Most of the respondents like to stay with children as well as grand children. Majority of the respondents are share feelings with a family member as well as friends.

\section{SUGGESTIONS :}

Suggestions for the older people: The older people who say in the family should build harmony with the family members, children, and relatives. Accept them with their limitations. Do not accept more from the family members. Try to keep contact with members when they come to meet and over the phone as much as you can. It is better to be financially sound by saving some amount for old age. Financial independence is a crucial for a comfortable retired life, so saving adequate money during the working life would help during the retirement life. A comprehensive life insurance to cover those older people living below poverty line must be evolved. Supportive equipment like hearing aids, spectacles, walking aids must be provided free of cost to those living below poverty line. Suggestion to the family members: Family members should give respect to the elders and to take care of them so that their children will watch them and do the same for them. Try to avoid conversation which will hurt the feelings of the elderly. Know their limitations and they are dependent on you. Children those who are near and far visit the parents regular base and talk to them so that they can recall the olden days and have satisfaction in life. The younger generation should become more aware of the problems of the aged and they should treat them with honor and respect of considering them not a burden.

\section{CONCLUSION :}

The process of ageing contributed different changes in human body that may be motor disability impairment of sensory perceptions, deterioration of cells, the relationships include family members, relatives, friends and spouse social support. Migration to cities in search of better opportunities, migrating overseas and breakdown in relationships etc. also contribute to isolation of the aged. This brings to the fore the need for social security and protection for the aged who becomes more dependent on others for even day to day needs. In this context it is the medical and emotional want that medically, early diagnosis is difficult in elderly people. It is not a fact that growing old should be a time of dismay and withdrawal from everything around Today its nuclear family and speedy Physical ill health, relationship of the elderly, social support and psychological factors are causing social problems for the elderly. The elderly members of the family often get a feeling of being neglected, which result in insecure feeling that they are a burden for the family. This is a universal 
problem and once aging starts many problems arise and it will be often too late when a disease is diagnosed. In some cases they suffer in silence or once it is brought to the notice of the family, they ignore their complaints attributing it to aging. Youngsters are hesitant to spend money and time for the aged. Communication barriers also contribute to the problems. Thus, when the examination of the patient becomes difficult only a 'specially trained' medical practitioner (Geriatrician) can diagnose the silent typical symptoms of the aged patient need more attention.

\section{REFERENCES :}

[1] Anand U.K.( 2001). Dilemmas of aged in the New Millennium, Contemporary Social Work Department University of Lucknow. Vol .Xviii.

[2] Bose Ashish (1982). Aspects of Ageing in India. Social Action, Vol, 32 pp 1-19.

[3] Asiya Nasreena (2004). Care of elderly in changing family scenario. Perspectives in social work, Vol.XLX, no.3pp-33-36.

[4] Rani Pushpa Mary (2001). Institutionalizations care of the aged. Ageing and human development: Global perspective, New Delhi.

[5] Loloyd Sherlock (2000). Population ageing in developed and developing Regions: Implementation for health policy. Social Science and Medicine, 51(6), 19-21.

[6] Kapoor S and Kapooe A, (2000) Let us care for our older women. Research and development Journal, 6(1), 19-21.

[7] D’Mello Laveena, Monteiro Meena (2016). Age Related Problems of the Elderly and Their Coping Mechanisms. International Journal of Engineering Research and Modern Education (IJERME), 1(1), 723-729, ISSN (Online): 2455 - 4200.

[8] Shyam ,Rahhey, Yadav Sudesh(2002). A study of Depression, self Esteem and social amongst Institutionalized Aged. Journal of personality and clinical studies Vol.18 pp 78-76.

[9] Joja Thoromas (2003). Naturopathy and yoga for Geriatric Care. Help Age Indian-Research and Development, $9(1)$.

[10] Goorman M. and Heslopa (2002). Poverty, Policy, Reciprocity and older people in the South. Journal of International development, pp 1143-1151.

[11] Devi S.B. (2005). Challenges and issues in formal care giving . Indians Journal of Gerontology, 19 (4). 